\title{
Breast biopsy: the harvesting of lymph nodes presenting as lumps in a Nigerian community indicates that preventive cancer education is succeeding
}

\begin{abstract}
It has been suggested that establishing a pathology data pool promotes epidemiological analysis. A personal such data pool established among the Ibos of Nigeria covering 30 years revealed that 124 females presented with breast lumps on anticipating cancer. However, these proved to be just lymph nodes. On analysis, there were patterns that showed a growing awareness of the necessity for self breast examination in this community during the succeeding decades. Indeed, from the accumulated details, it is hypothesized that, in general, there are 3 biopsy indices of breast cancer awareness, namely, temporal trend of such awareness, eagerness in presenting lumps, and smallness of the delineated lesions. In all probability, these three parameters are research worthy epidemiologically all over the world.
\end{abstract}

Keywords: breast, lump, self-examination, lymph node, biopsy, health education, Nigeria, swelling
Volume 3 Issue 5 - 2015

\author{
Wilson Onuigbo \\ Department of Pathology, Medical Foundation and Clinic, \\ Nigeria
}

Correspondence: Wilson Onuigbo, Department of Pathology, Medical Foundation and Clinic, 8 Nsukka Lane, Enugu 40000I, Nigeria, Tel 2.35E+ 12, Email wilson.onuigbo@gmail.com

Received: October 19, 2015 | Published: November 27, 2015

\section{Introduction}

A publication from Birmingham(UK) dealt with the Histopathology Data Pool of surgical pathology with special reference to their potential use in epidemiological analysis. ${ }^{1}$ Similarly, Alistair Cochran, ${ }^{2}$ my fellow Pathology Trainee at the Glasgow Western Infirmary, Scotland, in the 1960s, pointed out recently that a major role of practising pathologists is to generate novel and original observations. Therefore, I present a 30-year analysis of the Histopathology Data Pool which I established after the cessation of the Nigerian Civil War in January 1970 with special reference to the findings on female breast lumps, which turned out to be lymph nodes. This appears to be largely a novel method of epidemiological research on the breast with reference to the indicators pointing to the parameters that are in keeping with the outcome of the ongoing preventive health education in this community. In all probability, this important field of cancer research will benefit from comparative studies worldwide.

\section{Materials and methods}

During the Nigerian Civil War (1967-70), the Histopathology Data Pool, which I had established at Enugu, the capital of the then Eastern Region of Nigeria, on my return in 1963 from the University Department of Pathology at the Glasgow Western Infirmary, was destroyed. When the war ended in January, I resumed data collection on 20th February, 1970. The 30-year data up to 19th February, 2000, are analyzed with strict reference to female breast lumps submitted to me by numerous doctors working in several hospitals attended by the Ibos, ${ }^{3}$ who constitute a major Nigerian ethnic group. The personal nature of the reference work was such that I manned it throughout in Enugu but in successive locations at the General Hospital, then the Specialist Hospital, next at the Teaching Hospital from which I retired in December 1990, and finally to the National Orthopaedic Hospital where I worked as an Honorary Chief Consultant Pathologist until retiring in March, 2015. I have throughout insisted on good documentation, i.e., the stipulation that reasonably well filled Request Forms must accompany the surgical specimens. Therefore, my accumulated Reports have been analyzed with special reference to the normal lymph nodes discovered in the breast specimens presumed to be cancerous.

\section{Results}

There were 124 females who presented with breast lumps which I diagnosed as lymph nodes. They were aged from 8 years to 72 years and averaged 31.5 years. On dividing the 30 -years period into the three roughly equal decades of the 1970s, 1980s, and 1990s, the total cases showed the rising figures of 4,30 , and 90 respectively. Fibro adenoma was the commonest clinical diagnosis, being recorded in 96 cases $(77 \%)$. These were followed in 7 cases by mammary dysplasia, a term which I prefer in consonance with an editorial in the British Medical Journal. ${ }^{4}$ Cancer, lymph node, and mass were mentioned in 3 cases each; mastitis, 2 cases; and one case each as lump, dermoid cyst, fibroma, adenoma, tumour or onchocyst. In the remaining 3 cases, no diagnostic term was offered. The commonest descriptive label was "lump" in 98 (79\%) instances. Others were "mass," 11 cases; "swelling," 9 cases; and "nodule," 4 cases. No description was supplied in 2 cases. Delay of one month occurred in 31 patients, while as many as $81(65.3 \%)$ of the patients attended within 6 months of noting their lump. The measured size in $\mathrm{cm}$ of the formalin fixed lesion during cut-up showed that up to $96(77.4 \%)$ of the specimens were quite small by measuring only up to $1.5 \mathrm{~cm}$. There were two cases without measurement as well as one fragmented specimen. Miscellaneous findings of interest included 2 patients aged 49 and 50 years in which anthracitic deposits appeared in their lymph nodes. There were altogether 66 doctors who submitted the specimens. The leading doctor sent $34(52 \%)$ specimens. Three others dispatched 6 cases each, while 53 doctors each supplied but a single specimen. Concerning the hospital sources, the Teaching Hospital situated in 
Enugu was responsible for $51(36 \%)$ cases, while 22 other hospitals in the town accounted for 34 specimens. There were 18 other towns from which the remaining 39 specimens were forwarded by doctors working in 25 hospitals. In other words, it is most likely that my catchment itself is significant.

\section{Discussion}

A study of the literature reveals two dimensions concerning the presentation of breast lesions, namely, some authors mention lymph nodes; others do not. On the one hand, there was one case of lymph node in my 1979 account of 128 adolescent breast masses in Ibos, ${ }^{5}$ while an English series of 132 cases of breast disease in outpatient surgical practice yielded 2 such lymph node cases. ${ }^{6}$ On the other hand, a Nigerian series ${ }^{7}$ from the western part of the country disclosed no lymphoid case; nor did some series from USA. ${ }^{8-10}$ and Saudi Arabia. ${ }^{11}$ Does this mean that lymph nodes within the breast are underestimated? Yes! Concerning them, Egan and McSweeny ${ }^{12}$ wrote from the United States thus: "They had been disregarded by surgeons and anatomists." A worthwhile parameter is the presentation according to the quadrant (Q) of the breast. The pattern in the above American series ${ }^{12}$ was close as follows: upper outer (UOQ), 6; lower outer (LOQ), 5; lower inner (LIQ), 2; and upper inner (UIQ). On the other hand, in the Ibo series, UOQ cases took the lead, far outclassing the rest with 33 cases. In contrast, LOQ occurred only 4 times, UIQ but once, and LIQ nil. This disparate distribution of UOQ may be a fluke because of the low number of cases whose quadrants were supplied. Otherwise, the explanation is to be sought in the realm of surgical statistics ${ }^{13}$ which has indicated that it is in that UOQ that $60 \%$ of breast cancers commence! Still on the data of Egan and McSeeney, they made the point that mammography may reveal the presence of obscure lymph node. They suggested that, if the discrete rounded lesions seen on the mammogram present a notch resembling a hilum or a radiolucent centre of fatty replacement. This may indicate an outlined lymph node. As my series has shown so many lymph nodes, it is proposed with a local radiologist to undertake a search of the collected mammograms in order to delineate Ibo patterns of this intriguing lesion. In 1978, the British Medical Journal ${ }^{14}$ drew attention to the public awareness then being heightened due largely to popular journalism. Of late, awareness has been receiving increasing attention. Thus, when he considered the Arab world, Hadi ${ }^{15}$ lamented the fewness of the related health education programmers. From Australia, Hill and associates ${ }^{16}$ concluded that a large proportion of women will take some active steps to guard against the disease provided that there are favorable conditions. Perhaps, as documented in the United States,${ }^{17}$ the effect of such education on the black race is unfavorable due partly to cultural beliefs and attitudes. Therefore, the question arises as to how far black Ibo females show awareness of breast disease. Clearly, the present study has revealed a positive temporal trend during three decades. This trend also showed up by way of the early attendance of most of the sufferers. Thus: presentation within 6 months was of the order of $65.3 \%$. Furthermore, the smallness of their lesions is significant, via; patients with lesions measuring only up to $1.5 \mathrm{~cm}$ were fully $77.4 \%$ of the cohort. Accordingly, although lymph nodes are usually obscure on account of their size, ${ }^{12}$ they were so studiously palpated among the Ibos as to be felt even as tiny lumps. Moreover, steps were taken to present personally to the local doctors for biopsy.

\section{Conclusion}

On account of my above data, I would like to hypothesize that awareness of breast disease in a community, especially a developing one, may be assessed by employing three decisive indices, namely, temporal trend, early in presentation, and small dimension of lesions. These three parameters were utilized in this series as follows:

I. The respective catchments were 4,30 , and 90 cases during the 1970 s, 1980s, and 1990s.

II. $65.3 \%$ of the patients delayed for only a few months before presentations.

III. $77.4 \%$ of the lymph nodes were of diminutive dimensions. As I see it, the large numbers both of the requesting doctors and of their hospital bases and the comparatively detailed data they supplied ensured that a representative spectrum of the pattern of intramammary lymph nodes entered the net that I had cast carefully into my local histopathology data pool! In all probability, the outlined parameters are research worthy all over the world.

\section{Acknowledgements}

None.

\section{Conflicts of interest}

The authors declare that there is no conflict of interest.

\section{References}

1. Macartney JC, Rollason TP, Codling BW. Use of a histopathology data pool for epidemiological analysis. J Clin Pathol. 1980;33(4):351-355.

2. Cochran AJ. The role of practising pathologists in the generation of novel and original observations. J Pathol. 2001;193(1):1-2.

3. Basden GT. Niger Ibos. London, England. 1966:411-423.

4. Editorial: Benign proliferative lesions of the breast. $\mathrm{Br}$ Med $\mathrm{J}$. 1976;1(6018):1106-1107.

5. Onuigbo WI. Adolescent breast masses in Nigerian Igbos. Am J Surg. 1979;137:367-368.

6. Cox PJ, Li MKW, Ellis H. Spectrum of breast disease in outpatient surgical practice. J Roy Soc Med. 1982;75(11):857-859.

7. Ajayi OO, Adekunle O. Non-malignant breast masses in an African population. Br J Surg. 1973;60(6):465-468.

8. Baker RR. Out-patient breast biopsies. Ann Surg. 1977;185(5):543-546.

9. Stone AM, Shenker IR, MacCarthy K. Adolescent breast masses. Am J Surg. 1977;134(2):275-277.

10. Ferguson CM, Powell RW. Breast masses in young women. Arch Surg. 1989;124(11):1338-1341.

11. Altaf FJ. Pattern of breast diseases: King Khalid National Guard Hospital experience. Ann Saudi Med. 2001;21(3-4):239-241.

12. Egan RL, McSweeney MB. Intramammary lymph nodes. Cancer. 1983;51(10):1838-1842.

13. Russell RCG, Williams NS, Bulstrode CJK. Bailey \& Love's Short practice of surgery. London, England. 2000:763.

14. Breast lumps in adolescent girls. Br Med J. 1978;1(6108):260-261.

15. Maha SA, Hadi A. Breast cancer awareness among health professionals. Ann Saudi Med. 2000;20:135-136.

16. Hill D, Rassaby J, Gray N. Health education in the control of breast cancer. Aust NZ Surg. 1984;54(3):205-208.

17. Lannin DR, Mathews HF, Mitchell J, et al. Influence of socioeconomic and cultural factors on racial differences in late-stage presentation of breast cancer. JAMA. 1998;279(22):1801-1807. 